\title{
Gamification as a Self-Direct Approach to Attain Instruction Concepts in Indian School System
}

\author{
Indula Mishra \\ Bal Bharati Public School, Noida, India \\ Email:indula.soni@gmail.com
}

How to cite this paper: Mishra, I. (2019) Gamification as a Self-Direct Approach to Attain Instruction Concepts in Indian School System. Open Journal of Social Sciences, 7, 227-232.

https://doi.org/10.4236/jss.2019.75019

Received: April 9, 2019

Accepted: May 24, 2019

Published: May 27, 2019

Copyright $\odot 2019$ by author(s) and Scientific Research Publishing Inc. This work is licensed under the Creative Commons Attribution International License (CC BY 4.0).

http://creativecommons.org/licenses/by/4.0/

c) (i) Open Access

\begin{abstract}
Science teaching does not always involve big lab set-up and high-tech apparatuses, however teaching learning process of science could be innovative in approach by using simple low-cost experimental models. This study identifies gamification as a self-directed literacy model to establish stimulatory tasks thereby achieving enhanced learning and application-based adaptability of the learnt skill-set. Model for gamification comprised of a five-step process: "understanding the target student population and relevant context of topic to be taught", "defining learning objectives", "structuring the experience", "identifying the resources", and "applying gamification elements". Target student population in Indian school system could be middle and high school students. Students can learn the gamification elements of activity to have ease in attaining the understanding of teaching model as the primary endpoint of this design.
\end{abstract}

\section{Keywords}

Active Learning, Gamification, Resources, Self-Directed Approach

\section{Introduction}

Science teachers often come across the challenges in clarifying key scientific concepts as applied science due to various limitations for example larger class strength, cumbersome practical models due to involvement of chemicals, apparatuses, individualized attention in the actual classroom settings. Thus, educators often land up becoming reluctant to carry activities in classroom that could yield in conceptualization of the key scientific phenomenon and their applicability in day-to-day activities.

Tools and models that can help students attain better outcomes by designing interventions to engage students in real-time activities could help fill such gaps 
of individualized attention for each student, self-directed learning, translate the scientific concepts in their daily activities and observations [1]. Such interventions take the form of small changes in context that might have larger outcomes. In addition, the effects of gamification can often be complemented with interventions that are longer lasting and longer-term adherence to a task at hand. In this review on methodology design, we focus on one such set of interventions collectively known as gamification [2].

Gamification [3] in simple definition is creating communities around a game that involves an intellectual work that is performed as a simple task explaining the concepts as an outcome of the simple task figuratively. It is a self-directed literacy model [4] to establish stimulatory tasks thereby achieve enhanced learning and application-based adaptability of the learnt skill-set could be the goal of this research design. With this gamification model, primary endpoints would establish self-directed learning of scientific key concepts, their application, and lastly understanding of the selectivity of scientific concepts by impending real-time needs.

\section{Methodological Implications and Potential Paradigms}

Research design to study the outcomes of gamification should be structured as a two-time point longitudinal evaluation of activity measures, one as the baseline assessment, and a subsequent one post implementation of the research activity paradigm. Model for gamification [5] comprises of five-step process: "understanding the target student population and relevant context of topic to be taught", "defining learning objectives", "structuring the experience", "identifying the resources", and "applying gamification elements".

One such example for using gamification as a tool could be to conduct a self-learning task at the household set-up. 7th or 8th standard students could be included as a study cohort through the learning process of the gamification task of a scientific concept that is taught as a classroom learning module. The application of five-step process of gamification model for this assignment is as follows: 1) Understanding the target student population and relevant context of topic to be taught: students could be taught about the concepts of energy loss, enthalpy and Gibbs energy [6] as a pre-assignment education module. 2) Defining learning objectives: students would be informed to read and understand the monthly electricity bill that they receive as their household amenity. They would be asked to identify the bill and what sections of the bill are modifiable by energy conservation methods. Students subsequently would review their house environment and the utilities that are involved in energy consumption for example: air conditioning, water heater usage, plugs and their usage. 3) Structuring the experience: Students would apply energy conservation methods for a month and thereby reducing the subsequent electricity bill. 4) Identifying the resources: Students would observe and understand to undertake specific activity related household functioning; for example: maintain the air conditioning appliance at a 
temperature based on daily weather changes, insulate the windows, and minimize the usage of door to minimize the inflow of heat energy from external environment (outside temperature) to the isolated environment (house temperature). 5) Applying gamification elements: students would involve in the activity, for example: to unplug unused appliance from the electrical supply lines, lower the temperature of the water heater and insulate the windows with insulating tapes. They could also be suggested to install a self-closing tool for the door, when door in open position is not needed. Students could be instructed to make a log for the daily activities that they performed for this project; and estimate what areas they worked on, what areas they could improve, and how did they observe loss of and use of electrical energy. Students can discuss about the findings once they return from the summer vacation back to school with both their logs of activities, pre-assignment and post-assignment electrical bills.

Students in this process can identify modes/usage of electrical energy in their household as a self-directed observation that they could relate to their electricity bill as the second step of the gamification process during their off-time. They will be able to effectively read and understand the electricity bill that they receive for their household electrical supply using a flow-chart design (Figure 1). Structuring of the experience of the students could yield key results. Some of the patterns for the loss of energy that the students might be able to identify as windows and door that remained open and unattended (their learning process of

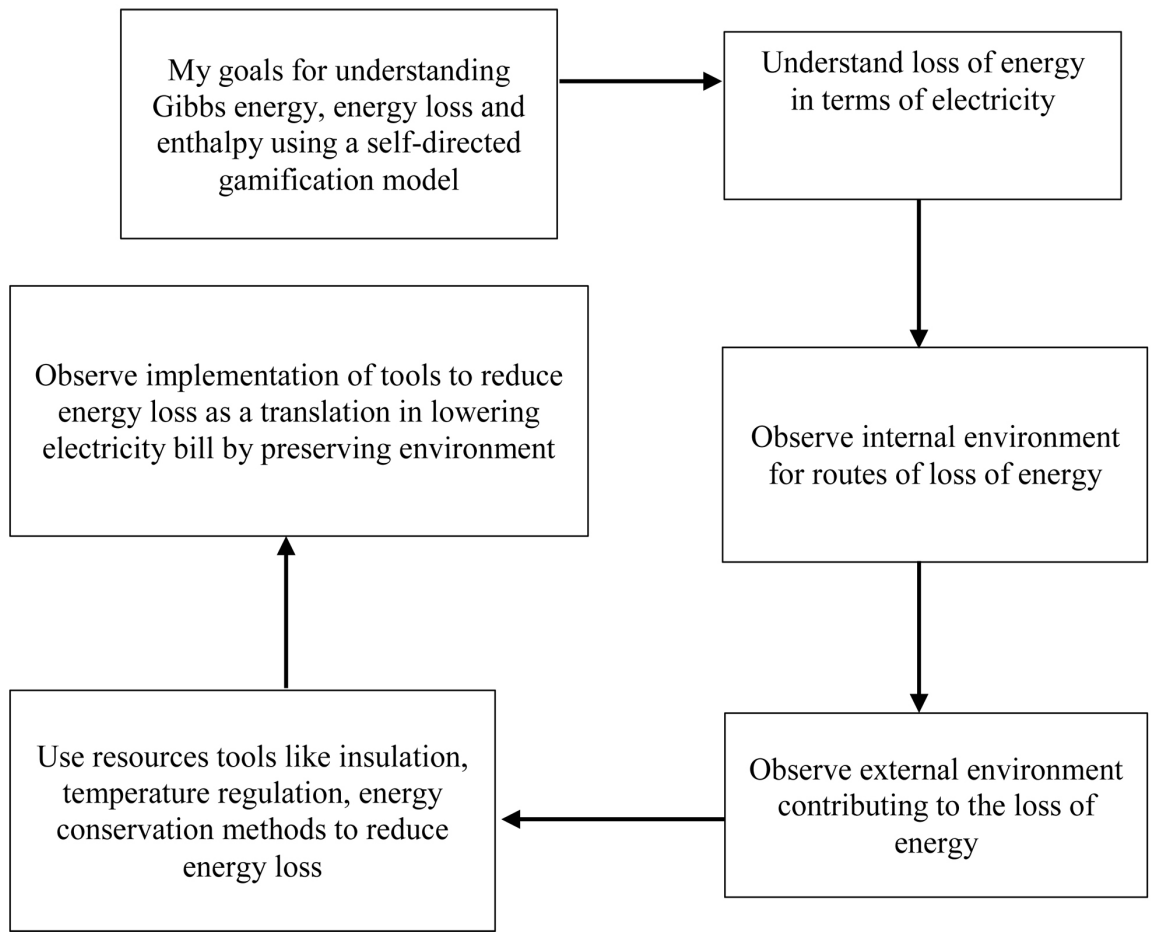

Figure 1. Application of the model of gamification in context of electricity consumption, cost reduction by integrating the scientific concept of energy loss, enthalpy, and Gibbs energy; and translation of cost-reduction activities to conserve electrical energy thereby reduce energy loss. 
addressing the question). Students could also identify how the loss of electrical energy might happen due to area of transduction of heat energy coming from the outdoors (external environment) (Figure 1). They can remark on unplugging of unused appliances and additionally searched for energy efficient light bulbs and tube lights (which would appear as an added self-directed application of the knowledge and learning; about the resources that were used and implemented as the fourth step of the gamification process). Lastly, students could search for methods of insulation for example, using insulation tapes on windows to reduce heat energy entering their household as resources (which could show their ability to apply the gamification elements as the final step of the process). The students could explain their electricity bill and the reduction of charges as an outcome of this study design. In this process, they could learn about a compounding chemistry phenomenon of energy loss, enthalpy, and parts and mechanisms of Gibb's energy translating the observation into scientific concepts.

Similar designs of gamification could be implemented in easing the understanding of scientific concepts. For example, molar indices (molar concentrations, molar volume, mole fraction etc.) or base units of the amount of substances could be explained in terms of a game to pick the card value corresponding to each element and develop different combinations of compounds/molecules. Such gamification tools could also be used in other areas of science (physics and biology) and other subjects such as mathematics, and social sciences (especially geography).

\section{Discussion}

A progressive school system is made up of progressive teachers/educators who develop students progressive by mind-set with wholesome intelligence, thus getting optimally prepared for independence executing tasks in a progressive society. There are difficulties that the science and mathematics teachers face in addressing the coursework and simultaneously facilitate the students to hypothesize the topics by application [7] [8]. One of the better skill-sets of a progressive and informed teacher is being a lifelong learner, who could facilitate a child learn by doing, by discovering and not just by listening to a presentation of factual knowledge. It is only in this active and creative process leading to discovery that the pupil finds engagement; and their concentration becomes spontaneous; ultimately providing satisfactory gains to the teachers.

The philosophy and mechanics of "learning by doing" using gamification concepts and initiative at the school system in India would support the students to gain academic growth in Indian school environment that is much needed to translate the applicability of academic expectancies. To the best available information, at our school, BBPS Noida, we have initiated this novel concept; and encouraged students to bring the scientific concepts in application by motivating the students to toy with practical ideas, filling in execution gaps, and emerging with innovations that matter. These original works of scientific art present the 


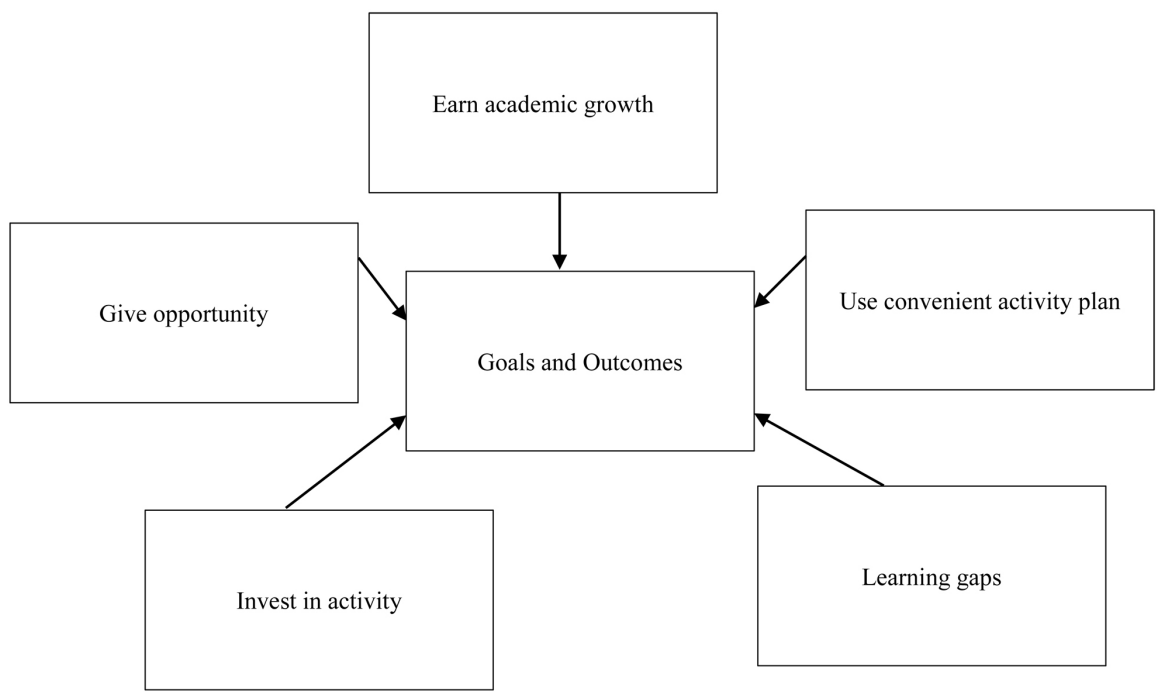

Figure 2. Overall outcomes of the gamification paradigm.

scientific excellence that may well develop in our classrooms and motivate students to implement their visions.

We as teachers through our teachings possess the responsibility of kindling in our students the scientific bent of mind, scientific curiosity and logical approach which, is essential for handling day to day situations in a mature way (Figure 2). It is our responsibility to integrate the students with information; and make compatible groups which work together, come up with marketable innovations ready for acceptance by the society, thus creating a foundation for them to become entrepreneurs, scientists in their community in Indian working class platform where startups are mushrooming and welcomed; and scientific instructions are emerging with notice to the western world.

\section{Acknowledgements}

I would like to thank the Bal Bharti public School, Noida India to sponsor this project. Lastly and importantly, I would like to conclude by thanking my mentor Mrs. Asha Prabhakar (Principal-Bal Bharti Public School) for reposing faith and guidance.

\section{Conflicts of Interest}

The author declares no conflicts of interest regarding the publication of this paper.

\section{References}

[1] Arnold, B.J. (2014) Gamification in Education. Proceedings of the American Society of Business and Behavioral Sciences, 21, 32-39.

[2] Grow, G.O. (1991) Teaching Learners to Be Self-Directed. Adult Education Quarterly, 41, 125-149. https://doi.org/10.1177/0001848191041003001

[3] Huang, W.H.-Y. and Soman, D. (2013) Gamification of Education. Research Report 
Series: Behavioural Economics in Action. Rotman School of Management, University of Toronto.

[4] Lampinen, M.J. and Fomino, M. (1993) Analysis of Free Energy and Entropy Changes for Half-Cell Reactions. Journal of the Electrochemical Society, 140, 3537-3546. https://doi.org/10.1149/1.2221123

[5] Li, D. (1998) "It's Always More Difficult than You Plan and Imagine": Teachers' Perceived Difficulties in Introducing the Communicative Approach in South Korea. TESOL Quarterly, 32, 677-703. https://doi.org/10.2307/3588000

[6] McGonigal, J. (2010) Gaming Can Make a Better World. TED Talks.

[7] Midgley, C., Feldlaufer, H. and Eccles, J.S. (1989) Change in Teacher Efficacy and Student Self- and Task-Related Beliefs in Mathematics during the Transition to Junior High School. Journal of Educational Psychology, 81, 247. https://doi.org/10.1037/0022-0663.81.2.247

[8] Panesar-Aguilar, S. and Aguilar, E. (2017) Promoting Effective Assessment for Learning Methods to Increase Student Motivation in Schools in India. Research in Higher Education Journal, 32, 1-16. 